\title{
ENFRENTAMENTO DOS DISGURSOS DE ÓDIO NA EUROPA E COLISÃO ENTRE LIBERDADE DE EXPRESSÃO VERSUS DISCRIMINAÇÃO A PARTIR DA SENTENÇA \\ ESPANHOLA 235/2007*
}

\author{
Manuel FONDEVILA MARÓN** \\ Rossana BARROS***
}

Sumario: I. Introdução. II. Panorama dos discursos de ódio na Europa. III. Normas da União Europeia pertinentes aos discursos de ódio. IV. O tratamento dos discursos de ódio pelo Conselho da Europa. V. Os discursos de ódio na jurisprudência do Tribunal Europeu dos Direitos do Homem. VI. A aplicação da normativa e jurisprudência comunitária nos Estados europeus: o caso da Espanha STC 235/2007. VII. Considerações finais.

VIII. Referências.

\section{INTRODUÇÃO}

A deflagração mais intensa dos efeitos do processo de globalização implicou na reorganização do mundo, especialmente a região ocidental, originando consequências de múltiplas conotações à tessitura social, econômica, política e cultural, sem deixar de transformar também as relações humanas.

Nesse contexto, observa-se a tendência de universalização dos discursos em torno de direitos humanos e o deslocamento das decisões políticas das instâncias soberanas nacionais para planos de justificação de decisões

* Estudio legislativo recibido el 16 de abril de 2018 y aceptado para su publicación el 18 de abril de 2020.

** ORCID: 0000-0002-2462-5510. Doutor em direito. Professor Serra Hunter de direito constitucional na Universidade de Lleida (Espanha).E-mail:manuel.fondevila@udl.cat.

*** ORCID: 0000-0001-5881-7783. Mestra em direito e instituicoes do sistema de justiça (UFMA Brasil, Maranhão). Advogada. Professora de Direito constitucional, Introdução ao estudo do direito, empresarial e civil na Faculdade Cest (Brasil/Maranhão). E-mail:rossana.barros@hotmail.com

Boletín Mexicano de Derecho Comparado, nueva serie, año LII, núm. 157, enero-abril de 2020, pp. 411-435. 
internacionais ou supranacionais, marcados pelo dinamismo e complexidade.

Nessa discussão, significativa parte do continente europeu tem demonstrado preocupação com enfrentamento dos discursos de ódio, considerando que esses ferem o princípio da igualdade e dignidade da pessoa humana, vulnerando grupos sociais inteiros por motivos de raça, gênero, concepções políticas e religiosas, etnia, condições socioeconômicas, entre outros.

Assim, são observados diversos instrumentos normativos afetos à matéria, bem como inúmeras iniciativas de conscientização e fomentação da tolerância nas relações sociais europeias.

Dessa forma, tornou-se importante discutir os principais avanços relacionados aos discursos de ódio, lançando bases para a melhor compreensão desses, aprendizado institucional para os sistemas jurídicos de um modo geral, bem como amadurecimento ante as dificuldades registradas. Deve-se notar que o discurso de ódio é apenas um dos tipos que compõem a classificação "crimes de ódio" (que incluem ameaças, crimes contra a integridade moral, genocídio, etc.), apesar da tendência atual de assimilar a parte com o todo (Fundación Abogacía Española 2018). Neste trabalho nos limitamos apenas ao primeiro

Com esse objetivo, traçou-se um panorama geral dos discursos de ódio na Europa, acompanhado da descrição das principais normas europeias pertinentes aos discursos de ódio. Abordou-se o combate europeu à discriminação, racismo, xenofobia e às condutas definidas como discurso de ódio.

A seguir, discutiu-se o tratamento dos discursos de ódio pelo Conselho da Europa, bem como o tratamento dos discursos de ódio a partir da análise da jurisprudência do Tribunal Europeu dos Direitos do Homem.

Na última seção do trabalho, analisou-se especialmente a sentença espanhola de número 235/2007, em que se pondera a colisão entre o direito de liberdade de expressão e a eventual prática de um discurso de ódio presente na negação da ocorrência do holocausto alemão, concluindo-se pela culpabilidade do réu.

Para tanto, adotaram-se os seguintes procedimentos de pesquisa: pesquisa bibliográfica e pesquisa normativa, utilizando-se abordagem qualitativa e quantitativa e análise de conteúdo para tratamento dos dados. 
A pesquisa bibliográfica compreendeu exploração de doutrina nacional e estrangeira sobre o tema em comento, incluindo livros e revistas selecionados em bibliotecas públicas e bases de dados como a HeiOnline.

A pesquisa normativa abrangeu espécies jurídicas pertinentes aos discursos de ódio, como Tratados, decisões, resoluções, entre outros, coletados páginas oficiais ${ }^{1}$ de informações sobre a União Europeia e Europa.

\section{PANORAMA DOS DISGURSOS DE ÓDIO NA EUROPA}

Em atenção às diversas espécies de violações de direitos humanas perpetradas mediante a prática de discursos de ódio, organismos internacionais lançaram mão de documentos que tipificam diversas formas de discriminação, estabelecendo o compromisso dos Estados no sentido de enfrentar crimes fundados nessa.

O conceito doutrinário de discurso de ódio é extraído da interpretação acadêmica de instrumentos internacionais como a Decisão-Quadro 2008/913, que considera incitação ao ódio comportamentos que: a) motivam publicamente à discriminação indivíduos ou grupos de indivíduos em virtude de raça, cor, religião, crença, ancestralidade ou origem; b) negam a existência de genocídios, crimes contra a humanidade e crimes de guerra, estes últimos definidos nos artigos 6,7 e 8 do Estatuto do Tribunal Penal Internacional.

Acrescenta-se que a referida Decisão-quadro define aos Estados membros a adaptação de suas leis de forma a considerar como circunstância agravante na cominação de penas e demais sanções penais a motivação racista e xenofóbica na prática de crimes.

Entre os principais documentos de Direito Internacional que subsidiam, de forma geral, o atual combate europeu aos discursos de ódio destacam-se a Convenção sobre a eliminação de todas as formas de discriminação racial (ONU 1965), Convenção para a Prevenção e a Repressão do Crime de Genocídio (ONU 1948) e Convenção Quadro para a Proteção das Minorias Nacionais (Conselho da Europa 1995).

1 European Union (EU) (s.d.), "Goals and values of the EU", disponível em: https:// europa.eu/european-union/about-eu/eu-in-brief_pt; CVRIA (s.d.) "Tribunal de Justicia da União Europeia", http://curia.europa.eu/jcms/jcms/j_6/pt; EUR-Lex (s.d.), "Acesso ao Direito da União Europeia", disponível em: http://eurlex.europa.eu/homepage.html?locale $=p t$. 
Nessa discussão, a compreensão da natureza dos discursos de ódio prescinde da análise dos discursos protetivos presentes na vasta normativa europeia, como a Decisão-Quadro relativa à luta por via do direito penal contra certas formas e manifestações de racismo e xenofobia, que como sugere o próprio título, objetiva punir de forma efetiva manifestações claras de racismo e xenofobia, incentivando a cooperação judiciária nessas áreas.

Portando significado ímpar no enfrentamento desses discursos, a Referida Decisão considera como discurso de ódio a incitação pública ao ódio em face de um grupo ou indivíduo por conta de elementos como raça, cor, pele, ascendência, religião ou origem, o que pode ser realizado por meio textual, imagético ou similar.

Considera-se ainda discurso de ódio a banalização ou negação pública dos crimes de genocídio, contra a humanidade e crimes de guerra definidos no Estatuto do Tribunal Penal Internacional e Estatuto do Tribunal Militar Internacional, quando essas atitudes configurem incitação à violência ou ódio, nos termos da Decisão-Quadro comentada.

Por último, o dispositivo normativo prevê ainda a igual punição da instigação, cumplicidade e participação intencional em atos relacionados a discursos de ódio, sendo que a motivação racista ou xenófoba é considerada circunstância agravante em todos os casos.

As motivações do discurso de ódio se insurgem contra as pessoas ou suas percepções, de forma a humilhá-las, despindo-lhes de sua personalidade, capacidade e experiências individuais, violando frontalmente o princípio da igualdade e dignidade humana.

Nessa discussão, não obstante o transcurso de mais de trinta anos e todas as soluções normativas adotadas, o fenômeno do ódio persiste, conforme pode ser observado em pesquisas de direito comparado, o que demonstra a existência de complexidade no tratamento desses crimes (Herrera 2014).

Apresentando dados sobre a abrangência e situação dos discursos de ódio na Europa, a Agência de Direitos Fundamentais da União Europeia (FRA 2015), entidade que tem como principal finalidade o aconselhamento independente aos agentes políticos, de forma a alimentar o debate, políticas e legislações em torno dos direitos fundamentais, publicou dois documentos emblemáticos. 
O Primeiro deles, Data in Focus Report-Minorities as Victims of Crime (FRA 2012), é um relatório que procurou quantificar as práticas de discriminação sofridas por grupos minoritários residentes em países da União Europeia, como ciganos, imigrantes e afrodescendentes.

Na pesquisa, concluiu-se pela maior vulnerabilidade dos indivíduos de origem cigana aos crimes contra o patrimônio e contra pessoas, o que é mais agravado pelas dificuldades de integração social enfrentadas por esse grupo, bem como a diferença de fenótipo com o europeu.

O segundo documento, Making Hate Crimes Visible in the European Union: Acknowledging Victims' Rights (FRA 2012), reúne informações a respeito dos discursos de ódio em variados países europeus e a respectiva reprimenda jurídica adotada em cada realidade nacional.

O relatório concluiu que Portugal é o país com menor número de estatísticas de práticas dessa natureza, o que pode ser explicado pela ausência de divulgação das informações sobre a criminalidade no país, bem como dificuldades na compreensão da abrangência dos discursos de ódio pelas instituições.

A Agência de Direitos Fundamentais da União Europeia descreve a história do continente europeu, como impregnada de discursos de ódio e intolerância, na qual os países contam com passado de escravidão, colonialismo, imigração e ditaduras, o que demonstra a dificuldade de precisar os discursos de ódio em uma definição legal homogênea e unificada (Herrera 2014).

Nesse clima de consideração da intolerância presente na história europeia, vários países lançaram mão de mecanismos muito específicos para combater discriminações, como a instituição de um tipo penal para a conduta de negar genocídios como o Holocausto.

Essas medidas se coadunam perfeitamente com a Decisão-Quadro relativa à luta por via do direito penal contra certas formas e manifestações de racismo e xenofobia, ato normativo que estabelece aos Estados membros o compromisso no sentido de reprimir condutas racistas, xenófobas, crimes contra a humanidade e de guerra, bem como a negação ou banalização pública desses.

Nessa discussão, é necessário conferir a atenção para a gravidade desses discursos, haja vista os impactos psicológicos e emocionais registrados nas vítimas, bem como a intimidação aos membros do grupo ofendido, atingidos pela brutalidade e extremismo (Herrera 2014). 
Destaca-se ainda a complexidade da liberdade de expressão em sociedades pluralistas, caracterizadas pela atribuição de igual valor às diversas vozes que integram a sua base cultural, o que não torna tal direito desprovido de limites (Herrera 2012).

\section{NORMAS DA UNIÃO EUROPEIA PERTINENTES AOS DISGURSOS DE ÓDIO}

A União Europeia tem apresentado importantes mecanismos no reconhecimento e enfrentamento dos discursos de ódio, fenômeno social que foge ao controle dos Estados nacionais, ante as facilidades de circulação de ideologias e dissipação de violências no mundo globalizado.

Nesse raciocínio, as relações interpessoais são transformadas pelo processo e globalização, caracterizado por elementos sociais, históricos, culturais e políticos que, somados, implicam em consequências notadamente humanas (Bauman 1999).

Ainda nessa mesma linha de pensamento, uma das principais características desse contexto, sob o ponto de vista argumentativo e discursivo, é a fertilidade das discussões em torno de direitos, haja vista as tendências de universalização do discurso moral (Barbosa 2003).

Em contrapartida, a fluidez do mundo moderno também ocasiona preocupações a todas as nações, tendo em vista o aprofundamento dos males espirituais e morais, refletido nas relações humanas (Santos 2006).

É nessa perspectiva que se compreendem os discursos de ódio, manifestações de discriminação em razão de sexo, idade, etnia, concepções políticas, condições socioeconômicos, entre outros, agravados devido a fluidez e redução de distâncias no mundo globalizado.

Além de constituir preocupação para diversas organizações internacionais, esses discursos também ocupam pauta na agenda das instituições supranacionais, como a União Europeia, e paulatinamente ocupam discussões em processos de integração intergovernamentais como o Mercosul. $^{2}$

2 Nesse sentido, destaca-se a criação de um grupo interministerial para enfrentamento dos crimes de ódio pela internet no contexto do Mercosul, como pode ser verificado no Secretaria Especial de Direitos Humanos do Ministério da Justiça (2016). 
É possível afirmar que as normas europeias atuais afetas aos discursos de ódio são resultado de um processo de amadurecimento institucional da integração, que conjugou o aumento do número de órgãos competentes para o tratamento da matéria com o aprendizado normativo dos regramentos anteriores.

No âmbito desse amadurecimento normativo, são consideradas normas basilares para o panorama legal que existe hoje na Europa a Convenção para a proteção dos Direitos do Homem e das Liberdades Fundamentais, que assume relevância no tratamento dos crimes motivados pela discriminação de pessoas.

Assim, o artigo 14 da referida Convenção proíbe expressamente toda e qualquer distinção fundada no sexo, raça, cor, língua, religião, opiniões políticas, pertencimento a minorias, riqueza, entre outros elementos.

Nessa discussão, entre os primeiros atos normativos europeus para tratamento dos discursos de ódio, destaca-se o Tratado que institui a Comunidade Europeia (CEE y EURATOM), assinado em 1957 e prevendo no artigo 13 o compromisso de reprimir toda e qualquer discriminação em razão da nacionalidade.

Além disso, o artigo 13 do mesmo Tratado prevê a tomada de medidas necessárias para combater a discriminação em razão do sexo, raça ou origem étnica, religião ou crença, deficiência, idade ou orientação sexual.

Lançando bases legislativas no contexto da repressão europeia dos discursos de ódio, o Tratado de Amsterdã (1999), revelou-se estratégico ao proibir tratamentos desiguais fundados no sexo, equiparando a remuneração entre homens e mulheres, conforme disposto no artigo 119.

Reiterando e aprofundando os princípios cidadãos já esboçados nos tratados anteriores, o Tratado de Lisboa (União Europeia 2008) foi imprescindível para o tratamento dos discursos de ódio na atualidade do processo de integração europeu, haja vista a instrumentalização mecanismos democráticos.

Associando de imediato a dignidade da pessoa humana ao processo de integração, o Tratado de Lisboa estabeleceu como pilares estruturantes da União a liberdade, democracia e igualdade, incluindo as minorias no rol de sujeitos albergados pelas normas protetivas, conforme o disposto no artigo 10.-A.

Sendo assim, a referida norma constitui inovação no âmbito da integração europeia, haja vista a tentativa de trazer ao ambiente institucional 
valores cidadãos de uma comunidade pluralista, fundada na não discriminação, solidariedade, tolerância e igualdade entre homens e mulheres.

Direcionando-se também a questões muito específicas e pontuais, como a ajuda humanitária, o Tratado de Lisboa previu a conformidade dessas com os princípios de imparcialidade, neutralidade e não discriminação.

Dessa forma, é possível observar que a natureza jurídica dos discursos de ódio enquanto grave violação de direitos foi sedimentada gradativamente com a sucessão de Tratados e atos normativos incorporados à política da União Europeia.

Entre os instrumentos mais significativos no tocante ao enfrentamento dos discursos de ódio, encontra-se a Decisão Quadro Relativa à Luta por via do Direito Penal contra certas Formas e Manifestações de Racismo e Xenofobia (Conselho da Europa 2008). Conforme disposto no referido documento, o principal objetivo da sua edição é conceder sanções penais efetivas e condizentes com discursos de ódio, melhorando e incentivando a cooperação judiciária nessa matéria.

A importância dessa decisão é observada na enumeração das condutas puníveis como discursos de ódio, haja vista a multiplicidade de mecanismos aptos a provocar agressões fundadas em discriminações, conforme o trecho a seguir:

Serão considerados puníveis como infrações penais determinados atos, tais como:

- A incitação pública à violência ou ao ódio dirigido contra um grupo de pessoas ou um membro de um desses grupos, definido com base na raça, cor da pele, ascendência, religião ou crença religiosa ou origem nacional ou étnica.

- A infração supramencionada, quando realizada através da difusão, por qualquer meio, de texto, imagens ou outro material.

- A apologia, negação ou banalização grosseira públicas dos crimes de genocídio ou contra a humanidade e crimes de guerra, tal como definidos no Estatuto do Tribunal Penal Internacional (artigos 6.o, 7.o e 8.o) e crimes definidos no artigo 6.o do Estatuto do Tribunal Militar Internacional, quando esses comportamentos forem de natureza a incitar à violência ou ódio contra esse grupo ou os seus membros.

Esta obra está bajo una Licencia Creative Commons

Atribución-NoComercial-SinDerivar 4.0 Internacional, IIJ-UNAM.

Boletín Mexicano de Derecho Comparado, núm. 157, enero-abril de 2020, pp. 411-435. 
A Diretiva 2012/29 (Parlamento Europeu 2012) tem o escopo de estabelecer princípios aplicáveis à proteção e aos direitos de vítimas da criminalidade em geral, que inclui as vítimas de discursos motivados pelo ódio, substituindo a Decisão-Quadro 2001/220/JAI do Conselho, primando pela maior clareza e avanço protetivo.

Entre os pontos mais relevantes da norma, observa-se a previsão de um tratamento especial às vítimas de discursos de ódio motivados pela discriminação de gênero, violação que compreende agressões nas relações íntimas, violência sexual, tráfico de seres humanos, casamentos forçados, mutilação genital, entre outros.

De uma forma geral, o documento assevera que as vítimas de discursos de ódio são vulneráveis aos riscos de vitimização secundária, intimidação e retaliação durante o processo penal, perigos identificáveis a partir de uma avaliação individual apta a sugerir medidas de proteção da integridade física e moral.

Nesse sentido, o documento prevê medidas protetivas considerando a maior fragilidade das vítimas desse tipo de prática conforme o disposto nos artigos 57 e 58 .

(57) As vítimas de tráfico de seres humanos, terrorismo, criminalidade organizada, violência em relações de intimidade, violência ou exploração sexuais, violência baseada no género e crimes de ódio, as vítimas com deficiência e as crianças vítimas tendem a sofrer frequentemente de uma elevada taxa de vitimização secundária e repetida, de intimidação e de retaliação. Deve ter-se particular cuidado ao avaliar se essas vítimas correm ou não o risco de sofrer essa vitimização, intimidação e retaliação, devendo partir-se do princípio de que essas vítimas terão necessidade de medidas de proteção especiais.

(58) As vítimas que tenham sido identificadas como vulneráveis a vitimização secundária e repetida, a intimidação e a retaliação devem beneficiar de medidas de proteção adequadas durante o processo penal. A natureza exata dessas medidas deve ser determinada através da avaliação individual, tendo em conta a vontade da vítima.

Outro documento europeu compreendido à luz da proteção de vítimas de discursos de ódio é a Resolução do Parlamento Europeu (Parlamento Europeu 2014), que contém recomendações à Comissão sobre estratégias para eliminação da violência contra as mulheres. 
O referido ato normativo exortou os Estados Membros a avançar na legislação e políticas protetivas de modo a combater as causas da violência, recomendando à União adoção das medidas cabíveis.

Outra norma de importância destacada no enfrentamento dos discursos de ódio na União Europeia é a Resolução do Parlamento Europeu sobre o Reforço da Luta contra o Racismo e os Discursos de Ódio (2013). Entre as principais manifestações de discursos motivados pelo ódio, a resolução elenca os seguintes: racismo, a xenofobia, o antissemitismo, a intolerância religiosa, o anticiganismo, a homofobia, a transfobia, entre outros. O documento considera a relevância de se recordar os massacres perpetrados sob fundamento racista e xenófobo ocorridos no desenvolvimento histórico da Europa, como forma de enfrentá-los no presente.

Para tanto, são enumeradas as seguintes políticas específicas, somadas às legislações penais dos Estados Membros: lançamento de estratégias globais na luta contra os discursos de ódio, práticas que promovam o encorajamento dos cidadãos para denunciar essas infrações, oferecendo-lhes proteção, adoção de uma Diretiva de Promoção da Igualdade pelo Conselho, entre outras iniciativas.

Para instrumentalização dos fins propostos pelo referido ato normativo ao processo de integração europeu, a resolução estabeleceu a compatibilidade entre as normas da União Europeia e dispositivos de direitos humanos afetos à liberdade de expressão. Além disso, compreendeu conhecimentos sedimentados por programas europeus afetos à promoção da cidadania, bem como a participação das organizações da sociedade civil em questão.

Destaca-se que a Resolução do Parlamento Europeu sobre o Reforço da Luta contra o Racismo e os Discursos de Ódio (2013) não é uma norma jurídica de eficácia vinculante, considerando-se sua força limita-se a comunicação a autoridades e órgãos como Presidente do Conselho Europeu, Conselho, Comissão, Parlamentos e Governos dos estados sobre seu conteúdo, sem constituir uma fonte genuína de obrigações a esses sujeitos políticos.

Entre os órgãos europeus mais destacados na promoção da não discriminação e repressão do racismo, da xenofobia, do antissemitismo, homofobia e das intolerâncias e da violência motivada por preconceitos que lhes estão associadas, se destaca a Agência dos Direitos Fundamentais (FRA 2015). 
Com esses mesmos objetivos relacionados ao reconhecimento e enfrentamento dos discursos de ódio, de modo a promover uma Europa regida pela tolerância entre as pessoas, destacam-se os seguintes atos normativos: Diretiva 2000/43 do Conselho, que proíbe distinções raciais ou étnicas e a Diretiva 2000/78 do Conselho, que prevê o tratamento igualitário no emprego.

\section{O TRATAMENTO DOS DISGURSOS DE ÓDIO PELO GONSELHO DA EUROPA}

Entre os atores políticos mais importantes no tratamento dos discursos de ódio da Europa, destaca-se o Conselho da Europa, organização internacional que promove o Estado de direito, democracia, direitos do homem e o desenvolvimento social, conforme o disposto no artigo 1o. do Estatuto do Conselho da Europa.

Constituindo a principal organização de defesa dos direitos humanos no continente europeu, o Conselho da Europa integra 47 Estados membros, dos quais 28 fazem parte da União Europeia, guiados pela Convenção Europeia dos Direitos do Homem.

Conforme o disposto no artigo 1o. da Convenção de Londres, o Conselho da Europa tem o objetivo de realiza uma união estreita entre os países, de modo a promover os ideais compartilhados e favorecer o progresso econômico e social, promovendo também a defesa dos direitos humanos, democracia pluralista e estabilidade na Europa.

Primando pelos direitos de livre expressão, liberdade de imprensa, reunião, igualdade e proteção de minorias, a organização tem se destacado pelas campanhas lançadas com a finalidade de descrever e enfrentar temas como o discurso de ódio, acompanhando diretamente o desempenho dos Estados membros nessa seara mediante órgãos de monitorização (FRA 2007).

Entre os principais órgãos de monitorização a serviço do Conselho da Europa na tarefa de enfrentar os discursos de ódio estão o Comité dos Peritos de Avaliação das Medidas contra o Financiamento do Terrorismo; Comissão Europeia contra o Racismo e a Intolerância; Comité Consultivo da Convenção Quadro para a Proteção das Minorias Nacionais, entre outros. 
Surgido após a Segunda Guerra Mundial com escopo nas finalidades já mencionadas, o Conselho da Europa capitaneou instrumentos jurídicos importantes para o enfrentamento dos discursos de ódio na Europa, como a Convenção Europeia dos Direitos do Homem (CEDH).

O referido documento é um dos tratados contemporâneos em matéria de direitos humanos, que segue a linha protetiva da Declaração Universal dos Direitos do Homem (ONU), impondo obrigações de natureza vinculante aos Estados Membros, como a garantia dos direitos humanos.

Constitui fonte dos direitos humanos no plano internacional, implicando no estabelecimento de regras voltadas para a solução de casos concretos, e edificação um sistema de fiscalização da observância das normas pelos Estados membros.

Após a data de entrada em vigor, a Convenção Europeia dos Direitos do Homem passou por várias modificações mediante instrumentos denominados Protocolos Adicionais, entre os quais se destaca o no. 12, que adicionou à Convenção a proibição de discriminações relativas ao sexo, raça, cor, língua, religião, convicções políticas, origem, condições socioeconômicas, entre outros.

Quanto à aplicabilidade da Convenção, essa é mediada pelo Tribunal Europeu dos Direitos do Homem, órgão internacional especial dedicado à prolação de sentenças e funções processuais, garantindo o respeito dos Estados pelos direitos e liberdades reconhecidos na Convenção.

Assim, o aprofundamento normativo da Europa em torno das normas de enfrentamento dos discursos de ódio relaciona-se diretamente com a incidência internacional da Convenção Europeia, bem como a jurisdição do Tribunal Europeu dos Direitos do Homem, em caso de descumprimento.

Entre os vários documentos sancionados pelo Conselho da Europa no tratamento dos discursos de ódio, destacam-se a Carta Social Europeia (1996), que prevê o direito à igualdade de oportunidades e de tratamento em matéria de emprego e de profissão, assim como a proibição contra a discriminação.

Igualmente importante, a Recomendação Geral no. 15, da Comissão Europeia contra o Racismo e a Intolerância, do Conselho da Europa, se relaciona com o combate ao discurso de ódio, assumindo fundamental relevância para a identificação do conceito de discurso de ódio e facilitando a hermenêutica em torno de tais condutas. 


\section{OS DISGURSOS DE ÓDIO NA JURISPRUDÊNGIA DO TRIBUNAL EUROPEU DOS DiREITOS DO HOMEM}

Sendo órgão internacional especial garantidor da observância da Convenção Europeia dos Direitos do Homem, o Tribunal Europeu de Direitos do Homem (TEDH) tem se destacado na missão de enfrentar os discursos de ódio, entendidos como grave violação de direitos humanos.

Quanto à sua natureza jurídica, o Tribunal Europeu dos Direitos do Homem é uma jurisdição internacional com sede em Estrasburgo, composto por um número de juízes igual aos dos Estados membros do Conselho da Europa signatários da Convenção para a Proteção dos Direitos do Homem e das Liberdades Fundamentais.

Embora seja composto por juízes provenientes de todos os Estados membros, esses encontram-se desvinculados das aspirações observadas nos seus países de origem, não representando esses nem seus requerentes, haja vista o compromisso com os direitos humanos em uma perspectiva continental.

Com relação ao enfrentamento dos discursos de ódio na Europa, o TEDH tem adotado uma linha de raciocínio rigorosa ante à prática de discriminações (não apenas sobre discursos de ódio), primando pela falta de justificação desse comportamento em uma sociedade contemporânea de cunho pluralista.

Por outro lado, em alguns casos concretos o mesmo Tribunal tem adotado uma interpretação mais flexível dos discursos de ódio, de forma a privilegiar o direito à livre manifestação do pensamento em confronto com outros.

Nesse sentido, destacam-se as seguintes decisões:

\section{Processo Moustaquim c. Bélgica}

Trata-se de caso de cidadão marroquino ameaçado de ser expulso da Bélgica em virtude da prática de supostos crimes e inconformado com a decisão de expulsão, haja vista o tratamento discriminatório.

Em sua defesa, alegou tratar-se de discriminação com base na nacionalidade, uma vez que aos cidadãos belgas acusados de infracções criminais não era imposta a pena de expulsão. 
Analisando o caso concreto, O TEDH não visualizou discriminação, tendo em vista as diferenças práticas entre a situação do marroquino e dos cidadãos belgas, que não podem ser expulsos do próprio país de origem.

No entanto, apesar de reconhecer como legítimo o fundamento do tratamento diverso, o TEDH reconheceu que a situação do cidadão marroquino é comparada à de vários cidadãos não belgas oriundos de outros Estados-membros da EU, portanto não passíveis de expulsão, haja vista a instituição da liberdade de circulação.

\section{Processo Luczak c. Polónia}

No caso concreto, agricultor de francês, de residência e trabalho na Polônia teve o acesso recusado no sistema de segurança social polaco especial, criado especificamente para apoiar agricultores polacos, e, portanto, inacessível a cidadãos não polacos.

Debruçando-se sobre a reclamação da parte, o TEDH entendeu pela similaridade entre a situação do cidadão francês e os agricultores polacos, tendo em vista a residência permanente, pagamento de iguais impostos e contribuição para o financiamento do sistema de segurança social.

\section{Processo Aziz c. Chipre}

Privado do direito ao voto devido a sua origem étnica turco-cipriota, bem como a lei A lei cipriota em vigor, que só autorizava os cipriotas-turcos e os cipriotas-gregos a votar nas eleições legislativas nos candidatos da sua própria comunidade étnica, o requerente submeteu reclamação ao TEDH.

Em sua defesa, o governo argumentou que a impossibilidade de votar decorria do facto de não existirem candidatos disponíveis em quem o queixoso pudesse votar, tendo em vista o abandono do território pela maioria da comunidade turca e suspensão da participação dessa nas eleições.

Decidindo sobre o caso, o TEDH interpretou que havia estreita ligação entre as normas eleitorais e a pertença à comunidade turco-cipriota, e como o governo não adotou normas eleitorais pertinentes à situação, 
a privação do voto constituía discriminação direta com base na origem étnica.

\section{Processo Weller c. Hungria}

No caso concreto, uma cidadã romena mãe de quatro filhos e casada com um nacional da Hungria não foi considerada apta a receber prestações de maternidade, haja vista a ausência de nacionalidade húngara.

Tentando solicitar as prestações o pai das crianças recebeu resposta negativa do governo, que em sua defesa afirmou que as prestações eram devidas somente a mães.

Decidindo sobre o caso, O TEDH concluiu pela discriminação praticada em face do marido em razão da paternidade e não do sexo, tendo em vista o direito dos pais adotivos e tutores do sexo masculino no sentido de requerer prestações, direito negado aos progenitores naturais.

No mesmo processo, os filhos alegaram a discriminação que fundamentou a recusa do Estado de pagar subsídio ao seu pai, tendo o TEDH considerado a queixa razoável e reconhecido a discriminação.

\section{Processo D.H. e outros c. República Checa}

No caso concreto, em escola da República Checa, realizaram-se variados testes para aferir da inteligência e da aptidão de alunos, de modo a fundamentar a decisão de transferi-los para escolas especiais, correspondentes a alunos com dificuldades de aprendizagem.

Considerando que os testes foram aplicados com base no nível da população checa maioritária, ocasionando maiores possibilidades de reprovação dos alunos de Roma, aconteceu de 80 a 90 por cento das crianças de Roma terem sido colocadas em escolas fora do sistema de ensino regular. Compulsando a matéria, o TEDH concluiu pela discriminação indireta.

\section{Processo Bączkowski e Outros c. Polônia}

No caso concreto, o presidente da Câmara de Varsóvia emitiu publicamente supostas comunicações de natureza homofóbica, vedando a 
realização de uma marcha de sensibilização da opinião pública sobre discriminação em razão da orientação sexual.

Apesar de o réu alegar em sua defesa a necessidade de evitar confrontos entre manifestantes, o TEDH concluiu que as declarações formuladas tiveram o potencial de influenciar autoridades competentes, mediante discriminações fundadas em motivos de orientação sexual, além de ferir o direito à liberdade de reunião e de associação, bem como o princípio da igualdade.

\section{Processo Paraskeva Todorova c. Bulgária}

Não obstante as recomendações do Ministério Público nacional no sentido de suspender a pena imposta a um indivíduo romano, os tribunais nacionais recusaram-se expressamente a seguir tal raciocínio, alegando a pertinência da condenação, haja vista a existência de uma cultura de impunidade entre a minoria romana, o que poderia servir de exemplo inspirador.

Analisando o caso, o TEDH concluiu pela violação do direito a um julgamento justo e isento de discriminação, bem como lesão ao princípio da igualdade, configurados no caso concreto.

\section{Processo Thlimmenos c. Grécia}

No caso concreto, a lei nacional impedia condenados criminais de exercerem profissão de revisor oficial de contas, por conta da presunção de ausência de honestidade e fiabilidade, características necessárias à realização do ofício.

Como o requerente foi condenado criminalmente pelo fato de recusar envergar o uniforme durante o serviço nacional, devido suas concepções pacifistas de Testemunha de Jeová, considerou a vedação descabida em sua situação particular.

Analisando os fatos, o TEDH concluiu pela ausência de fundamentos para impedir o acesso à profissão desejada, haja vista a falta de liame entre condenação e virtudes morais, afirmando assim a prática de discriminação. 


\section{Processo Wintersberger c. Áustria}

À luz da legislação nacional, portadores de deficiência gozam de proteção especial em face do empregador, sendo despedidos apenas após prévia aprovação por um comité especial, medida que pode ser aplicada retroativamente em caso de desconhecimento da enfermidade pelo empregador.

No caso concreto, o requerente preenchia perfeitamente esses requisitos, haja vista a sua deficiência, no entanto argumentou o tratamento discriminatório das pessoas sem deficiência, não sujeitas a possibilidade de avaliação, tampouco aprovação retroativa.

Assim, O TEDH concluiu pela razoabilidade do dispositivo, que justificava a discriminação reversa, declarando a queixa inadmissível, dessa forma.

\section{Processo Mondragón c. Espanha}

No caso concreto, um porta voz de um grupo parlamentar fez afirmações públicas sobre uma operação policial, argumentando que o chefe de Estado espanhol e chefe das forças armadas chefiava pessoas que haviam detido e torturado outras na referida operação.

Em uma cerimônia com o presidente do governo vasco, o parlamentar proferiu as seguintes palavras: "Como é possível ser fotografado hoje em Bilbao com o rei da Espanha, quando esse é responsável por proteger torturadores e impor o seu regime monárquico ao nosso povo por meio de tortura e violência?" (§10).

Tendo o Ministério Público apresentado denúncia ante as declarações públicas do parlamentar, o primeiro julgamento do Supremo Tribunal de Justiça do País Vasco considerou que essas foram realizadas no âmbito do direito à liberdade de expressão, e como tal, não deveriam ultrapassar os limites do mesmo, havendo a condenação do agente político.

Nessa discussão, o TEDH interpretou o caso à luz da liberdade de expressão e seus limites em um Estado democrático, considerando que a Espanha violou o artigo 10 da Convenção Europeia dos Direitos Humanos e o direito à liberdade de expressão do líder parlamentar, condenado pelas palavras relacionadas à pessoa e atuação do rei. 
A decisão do TEDH conferiu também um significado especial à liberdade de expressão na seara do discurso político, no qual esse direito tem imensurável valor aos eleitos pelo povo, representantes dos constituintes.

\section{Processo Castells c. Espanha}

À semelhança do caso anterior, o TEDH analisou a condenação de um membro do parlamento por insultos ao governo quanto à sua inércia diante da gravidade dos atos de terrorismo no País Vasco.

Nesse sentido, o TEDH afirmou a importância da liberdade de expressão no contexto político, considerando a relevância dessa para o bom funcionamento das instituições de uma sociedade democrática.

Dessa forma, se acordo com a referida interpretação, qualquer ingerência à essa liberdade fundamental exige padrões de controle rigorosos, especialmente no contexto político.

\section{Processo Merguer e Cros c. França}

Na condição de filha do autor de um processo de sucessão, a requerente viu-se incapacitada legalmente para receber de seu pai, em vida ou após a morte, mais da metade do patrimônio que lhe seria reservado caso fosse filha legítima.

Analisando o presente caso, a interpretação do TEDH suscitou a ausência de razões justificadoras da discriminação fundada no casamento, declarando a violação dos artigos $8^{\circ}$ e $14^{\mathrm{a}}$ da Convenção, que estabelecem a não ingerência do Estado no direito de constituir vida privada e familiar, e a proibição de quaisquer distinções fundadas no sexo, raça, cor, língua, religião, opiniões políticas, origem, condições socioeconômicas, entre outros.

\section{A APLICAÇÃO DA NORMATIVA E JURISPRUDÊNCIA GOMUNITÁRIA NOS ESTADOS EUROPEUS: O CASO DA ESPANHA STC 235/2007}

Diante de todo exposto, é possível observar uma tendência generalizada de enfrentamento dos discursos de ódio no continente europeu, tanto a partir 
das iniciativas do Conselho da Europa, como também em órgãos específicos do processo de integração vivenciado na União Europeia.

Nessa discussão, a concepção acerca da liberdade na Europa diferencia-se da que pode ser observada na realidade dos Estados Unidos, onde prevalece uma interpretação mais liberal em torno desse direito. Assim, a liberdade de expressão é proclamada, do ponto de vista constitucional, como direito limitado e exercido dentro de certos limites, de forma a evitar abusos, casos em que os direitos lesados podem ser mais privilegiados nas vias jurisdicionais (Ubillos 2008).

Tendo em vista o teor da Convenção Europeia, considerável parte dos Estados que ratificaram seu conteúdo tipificaram a conduta de negar ou minimizar o extermínio sistemático dos judeus durante o regime nazista, o que não aconteceu sem controvérsias.

Um exemplo disso é a existência de um tipo penal para a negação do Holocausto, considerada constitucional por países como a Alemanha e descabida em ordenamentos como o espanhol, conforme poder ser observado no Acórdão do Tribunal Constitucional 235/2007, que resolve a questão da inconstitucionalidade no artigo 607.2 do Código Penal.

Trata-se da condenação em primeira instância de um cidadão envolvido em suposta incitação de ódio, através na negação ao genocídio de povos judeus durante o regime nazista, Holocausto.

Conforme o disposto na decisão restou comprovado o envolvimento do réu, proprietário de uma livraria local, com distribuição, divulgação, e venda de materiais e publicações negando o genocídio praticado contra judeus, além de justificar tal fato.

Do ponto de vista jurídico, o caso suscitou o conflito entre a liberdade de expressão, amparada pelo art. 10 da Convenção Europeia dos Direitos do Homem e o tipo penal contido no art. 607,2 do Código Penal espanhol, reduzido aos seguintes termos:

Difundir por quaisquer ideias meios ou doutrinas que negam ou justificar os crimes de genocídio ou destinados a reabilitar regimes ou instituições que protegem tais práticas, fundamento legal utilizado para a condenação do reú em primeira instância.

Nessa discussão, a Audiência Provincial de Barcelona suscitou a questão da inconstitucionalidade do referido dispositivo normativo, adotando uma interpretação contrária à dominante em outros países como a Ale- 
manha, de forma a privilegiar o direito à livre manifestação do pensamento.

Assim, a decisão pontuou que esse direito ultrapassa a natureza de liberdade individual, conformando elementos de construção do sistema político democrático, abrangendo além da livre expressão, o direito de se comunicar livremente, exprimindo opiniões eventualmente conflitantes, o que promove uma sociedade aberta e pluralista.

Sendo assim, a liberdade de expressão engloba não apenas as informações ou ideias consideradas inofensivas ou indiferentes, mas também às que ofendem, chocam ou inquietam o Estado ou qualquer parte da população, conforme os termos da decisão.

Observa-se então que o julgado privilegiou as liberdades ideológicas, participação, expressão e informação, incluídas na mera difusão de ideologias, o que não se configura contrariedade com os preceitos constitucionais, mas garantias de não intervenção do Estado na vida privada do indivíduo.

Além dessas considerações, a decisão ainda sustentou o caráter relativo da liberdade de expressão, pontuando a possibilidade de restrição dessa em caso da prática de atos com a intenção de discriminar indivíduos ou grupos em razão de qualquer condição ou circunstância pessoal, étnica ou social.

Interpretando a abrangência e finalidades do dispositivo punitivo espanhol, concluiu-seque a conduta proibida não se relaciona incitação a discursos motivados pelo ódio, mas mantém correspondência direta com a liberdade de expressão.

Assim, entendeu-se também que além de restringir significativamente a livre manifestação do pensamento, o artigo do Código Penal espanhol ainda fere a liberdade científica (artigo 20.1 b) e de consciência (artigo 16 $\mathrm{CE})$.

Nessa perspectiva, a decisão pontuou que a negação consiste em uma mera expressão de ponto de vista sobre determinados fatos, portanto a prática de incitação ao ódio não deve ser presumida, mas avaliada nos casos concretos.

No entanto, convém observar que a inconstitucionalidade suscitada no Tribunal não é presumida em todos os casos de negação do genocídio, incidindo apenas quando a conduta não contenha insultos e intenção clara de incitar o ódio. 
As nuanças interpretativas presentes na referida decisão provocam celeuma na doutrina, havendo autores que concordam com a supremacia do direito à livre expressão e outros que condenam o ponto de vista, exaltando o princípio da dignidade da pessoa humana, igualdade e não discriminação.

Nessa discussão, há variedade de autores com posicionamentos contrários, para os quais os argumentos apresentados em favor da constitucionalidade da conduta de negar o genocídio, banalizam os crimes hediondos de ódio, desprezando a dignidade e sofrimento das vítimas. Nesse raciocínio, o precedente marca uma nova tendência na interpretação constitucional dos discursos relacionados à apologia do genocídio na Europa, haja vista a valorização do princípio de livre manifestação do pensamento (Espino 2008).

No entanto, a virada interpretativa, além da densificação do entendimento jurisdicional também ocasiona vários riscos como fomentação de um clima de intolerância, nocivo para a convivência democrática (Espino 2008).

Na sua argumentação o Tribunal aduz, entre outros elementos, a falta de relação entre negação do genocídio e dolo de incitar o ódio racial ou menosprezar determinado grupo social. Além disso, a decisão também pontua que a liberdade de expressão abrange a busca da verdade histórica.

Nessa discussão, a mera negação tipificada na Lei Penal espanhola não implica na mera desconsideração de um fato histórico qualquer, senão um dos mais graves acontecimentos presenciados pela humanidade. Além disso, o genocídio de judeus restou provado através de elementos incontestáveis, o que afasta a justificativa de neutralidade científica em sua negação (Espino 2008).

Seguindo o raciocínio contrário, outros autores consideram acertada a decisão do tribunal, que adotando uma linha interpretativa oposta ao entendimento majoritário nos países europeus, privilegia o direito de livre manifestação de pensamentos.

Nesse sentido, o caso discutido congregaria principalmente a liberdade de manifestação de ideologias e pensamentos, reconhecida pelo artigo 16 da Constituição, princípio compatível com uma sociedade aberta e pluralista, que protege a circulação de ideias, aceitas ou não pela sociedade. 
Ainda nesse raciocínio, o julgado revelaria significativa importância para a proteção da que a liberdade de investigação científica, haja vista o constante processo de reformulação de verdades científicas, que não pode ser engessado pela norma jurídica, sob pena de ameaça à neutralidade.

A nosso ver, a sentença 235/2007 trouxe elementos para amadurecimento do debate em torno da colisão entre, de um lado, liberdade de expressão, consciência e crença e de outro, dignidade da pessoa humana e princípio da igualdade.

É certo que, dada a crueldade e horror do genocídio cometido contra o povo judeu durante o regime nazista, vários países como a Alemanha adotaram condutas bastante restritivas no sentido de proibir a negação do Holocausto, o que demonstra a observância do passado na prevenção de violências futuras.

Apesar de ter um fundamento razoável, esses dispositivos podem causar injustiças em casos concretos, tendo em vista a associação imediata da negação em si à prática de incitação de ódio, o que deve ser analisado em casa situação.

Quando essa discussão é contextualizada com a estruturação das instituições marcadas pela complexidade, a exemplo das contemporâneas, a pluralidade de vozes, ideais e discursos dificulta sensivelmente a formação de consensos e alcance da unanimidade (Habermas 1990).

Assim, para possuir fundamentos legítimos, tais instituições devem ser justificadas pelo diálogo argumentativo e inclusivo entre os membros de uma comunidade, o que é possível apenas mediante a comunicação e reflexão acerca dos argumentos mais razoáveis (Habermas 1990).

Nessa discussão, é importante observar que os limites argumentativos são tênues entre o privilégio de um princípio e a menor profundidade semântica de outro, sendo aconselhável adotar instrumentos de equilíbrio no processo interpretativo.

No caso da referida decisão, observa-se que nem todas as negações de genocídios são amparadas pela liberdade de expressão, mas tão somente aquelas que não contém insultos ou ofensas diretas e finalidade clara de incitar o ódio.

Apesar do acerto da decisão no tocante à liberdade de expressão, consciência e crença, não concordamos com o argumento de que esse raciocínio seja necessário para garantir a neutralidade científica, como foi apontado por autores favoráveis ao entendimento. 
É certo que as ciências, como forma privilegiada de construção e justificação do saber, sujeitam-se à constante revisão de seus pressupostos e modos de conceber fenômenos determinados, no entanto esse não é elemento suficiente para justificar a inconstitucionalidade do crime de negação do genocídio.

Como já foi aprofundado, o tipo penal conta com vários argumentos que apontam pela sua inadequação jurídica, mas a neutralidade científica não pode ser inscrita entre esses fatores.

Isso porque é admissível que a ciência assista a reformulação dos seus pressupostos quanto ao crime de genocídio, sem implicar, porém na negação desse acontecimento lamentável, tendo em vista o conjunto probatório incontestável e as lições que jamais devem ser esquecidas pela humanidade.

\section{CONSIDERAÇÕES FINAIS}

Em atenção às violações perpetradas através dos discursos de ódio, organismos internacionais tipificam diversas formas de discriminação, firmando também o compromisso dos Estados com seu enfrentamento.

Motivados por fundamentos de sexo, raça, etnia, concepções políticas e religiosas, entre outros elementos, os discursos de ódio violam frontalmente os princípios da dignidade da pessoa humana e igualdade, através da humilhação de pessoas e intimidação de grupos sociais.

Apesar da adoção de vários instrumentos jurídicos repressivos, realização de campanhas educativas e fomentação de uma consciência humana pautada na tolerância, os discursos de ódio ainda persistem na Europa, o que demonstra a complexidade do problema.

Nessa discussão, a realidade européia tem se destacado pela quantidade e qualidade de disposições normativas adotadas com a finalidade de reprimir os discursos de ódio, haja vista os instrumentos adotados por órgãos da União Europeia como Parlamento e Comissão, bem como iniciativas desenvolvidas pelo Conselho da Europa, organismo internacional imprescindível para a defesa de direitos humanos.

Essa tendência protetiva também tem sido observada no Tribunal Europeu de Direitos do Homem, que em uma série de precedentes, tem mantido interpretações garantistas às partes lesadas, afirmando a existên- 
cia e incitação de discriminações, bem como adotando as medidas para corrigi-las.

No caso do Tribunal Constitucional da Espanha, adotou-se posicionamento mais flexível, quanto a inconstitucionalidade do crime de negação do genocídio, demonstrando amadurecimento interpretativo quanto aos conflitos entre liberdade de expressão e não discriminação, além de prestigiar o princípio de presunção da inocência.

Consequentemente os casos futuros demandarão um maior apego às suas circunstâncias particulares, de modo a caracterizar ou não as discriminações, implicando também no aprimoramento do trabalho argumentativo em torno dos diferentes pontos de vista, elemento imprescindível para o desenvolvimento de uma sociedade pluralista.

\section{REFERÊNCIAS}

AgÊnaia dos Direitos Fundamentais da União Europeia. 2012. "Data in Focus Report -Minorities as Victims of Crime", disponível em: https://fra.europa.eu/sites/default/files/fra-2012-eu-midis-dif6_0.pdf.

AgÊnaia dos Direitos Fundamentais dA União Europeia. 2012. "Making Hate Crimes Visible in the European Union: Acknowledging Victims' Rights", disponível em: https://fra.europa.eu/sites/default/files/ fra-2012_hate-crime.pdf.

AgÊnaia dos Direitos Fundamentais da União Europeia. 2015. "O crime de ódio na União Europeia", disponível em: https://fra.europa. eu/sites/default/files/fra-factsheet_hatecrime_pt_final.pdf.

Barbosa, A. F. 2003. O mundo globalizado: politica, sociedade e economia, São Paulo, Contexto.

BAUmAn, Z. 1999. Globalização: as consequências humanas, Rio de Janeiro, Jorge Zahar Editor.

Centro de Estudos JudiciáRIOs. 2013. Jurisprudência do Tribunal Europeu dos Direitos do Homem: casos nacionais, Lisboa, Centro de Estudios Judiciários.

EsPINO, M. L. S .2008. “Comentario a la STC 235/2007 de 7 de noviembre, por la que se declara la inconstitucionalidad del delito de negación de genocidio", Revista para el Análisis del Derecho, 2.

Fundación de la AbOGacía EsPañola. 2018. Delitos de odio. Guía práctica para la abogacía, Madrid, Fundación Abogacía Española.

Esta obra está bajo una Licencia Creative Commons

Atribución-NoComercial-SinDerivar 4.0 Internacional, IIJ-UNAM.

Boletín Mexicano de Derecho Comparado, núm. 157, enero-abril de 2020, pp. 411-435. 
Habermas, J .1990. "Soberania popular como procedimento", Novos Estudos Cebrap, São Paulo, 26.

Herrera, D. M. 2014. "Libertad de expresión: ¿derecho ilimitado según el TEDH? Del discurso de odio al crimen de odio", Estudios de Deusto, 2(62).

Herrera, D. M. 2014. “¿Cuándo el «hate speech» se convierte en «hate crime?» Libertad de expresión y derecho internacional según el TEDH", Revista de la Facultad, Córdoba, 2(2).

Parlamento Europeo. 2012. "Directiva 2012/29/UE del Parlamento Europeo y del Consejo", Diario Oficial de la Unión Europea (1).

Santos, M. 2006. Por uma outra globalização: do pensamento único à consciência universal, Rio de Janeiro, Record.

Secretaria Especial de Direitos Humanos do Ministério da JustiçA. 2016. Raadh, Paises firmam 11 acordos para garantia de direitos humanos no Mercosul, 27 outubro, disponível em: http://wrwre.sdh.gov.br/noticias/2014/novembro/raadh-paises-firmam-11-acordos-para-garantia-de-direitos-humanos-no-mercosul.

UBillos, J. M. B. 2008. "La negación del holocausto en la jurisprudencia del Tribunal Europeo de Derechos Humanos: la endeble justificación de tipos penales contrarios a la libertad de expresión", Revista de Derecho Político, 71-72. 